\title{
Co-occurrence of Disease Analysis using Association Rule Mining based on Apriori Algorithm
}

\author{
D. Sheila Freeda \\ Scholar, Bharathiyar University, Coimbatore, Tamil Nadu, India \\ M. Lilly Florence \\ Professor, Adhiyamaan College of Engineering, Hosur, Tamilnadu, India
}

\begin{abstract}
Data mining consist of analysis of massive data from various sources and retrieving useful information. This information can be converted to knowledge about future and past. Today huge amount of data is stored in healthcare system, these data includes patient details, disease information, doctors details, etc. With the help of data mining techniques useful decision can be made in disease curing and disease analysis. Apriori algorithm is an influential algorithm for decision making. In this paper the authors had implemented association rule mining based aproiri algorithm for finding co-occurrence of disease with the help of medical repositories.
\end{abstract}

Keywords: Association Rule Mining, Apriori Algorithm Data Mining.

\section{INTRODUCTION}

Nowadays there are many research is using data mining techniques for knowledge discovery from massive data. Data mining has many functions like classification, association, clustering and prediction. Decision making can be successfully done by transforming the information into knowledge. In this paper we implemented association rule based Apriori algorithm to extract knowledge from medical repositories for predicting the co-occurrence of diseases by a patient. Medical diagnosis is an important issue but complicated task, it needs to be analysis accurately and efficiently. Manual analysis and decision making on medical data is complex and not safe. Appropriate and automated decision making system can help in achieving less death rate. Hence the health care data is used in this work. In this work the authors are trying to find a correlation among diseases, so that if a patient is suffering with one disease, he/she may get the correlated diseases also. So we can alert and prevent the patient from diseases. The data for this work is collected from various hospitals across Krishnagiri district.

The other sections of this paper is organized as; section 2 describes the previous work carried out in this research area, section 3 and 4 introduces the association rule mining and apriori algorithm. Section 5 describes the medical data what we have used in this work. Section 6 explains the results and finding outs. Conclusion and future work are briefs in section 7.

\section{RELATED WORKS}

In [7] the authors were made an attempt to find any relationship in a clinical database. They also describes the data mining processes. In [8] the authors implemented association rules for medical data to find association among attributes. The authors in [1] proposed apriori data mining based on association rule for finding frequency of disease by patients. Clinical stat correlation prediction was developed to extract information from healthcare database which predict the relationship among primary disease and secondary disease [2]. In [3] the authors presented a methodology to identify the locally frequent diseases by implementing apriori mining technique. In this work the author collected data from medical centre and generate a frequent pattern to identify the frequent disease. In [5] the authors studied current technique of knowledge discovery in medical database using data mining. They also carried out some comparative study among techniques and concluded that the association rule mining perform well for medical data set. In [6], the author surveyed various application of association rule mining in medical data in areas of nosocomial infections, adverse drug reactions, etc. By understanding the previous work carried out by various 
researchers in the area of data mining of disease analysis, the current work of the author is unique and it is need and important for the society.

\section{ASSOCIATION RULE MINING}

Association rule mining was introduced by Agrawal and others during 1993. They worked for optimization of many algorithm like sampling, adding reference point, declining rules, etc. Association rules are if/then statements which is used to expose relationships between unrelated discrete data in a database or information repository. The main aim of this work was exploring the association rule mining to all the field of research. Association rule mining finds the association among item sets of massive data. Many researchers are using association data mining for information retrieval, information science and many other fields.

Let $D$ be a database with tuples as set of transactions. Let $I=\left\{i_{1}, i_{2}, . . i_{m}\right\}$ be set of items. An association rule is an implication of the form $\mathrm{U} \quad \mathrm{V}$ where $\mathrm{U}, \mathrm{V} € \mathrm{I}$ and $\mathrm{U} \cap \mathrm{V}=\Phi$. The rule $\mathrm{U} \longrightarrow \mathrm{V}$ holds for a transaction with support 's' and confidence 'c'. Support is an indication of how frequently the item-set appears in the database. Confidence is an indication of how often the rule has been found to be true. The support and confidence of a rule is calculated as follows;

$$
\begin{gathered}
\text { Support }(\mathrm{A} \rightarrow \mathrm{B})=\mathrm{P}(\mathrm{AUB}) \\
\text { Confidence }(\mathrm{A} \rightarrow \mathrm{B})=\mathrm{P}(\mathrm{B} / \mathrm{A})
\end{gathered}
$$

The mining rule is generated with minimum support threshold which is applied to find all frequent item-set in a database and minimum confidence threshold is applied to these frequent item-set to form rules.

\section{APRIORI ALGORITHM}

Apriori is proposed by Agrawal and R. Srikant in 1994. It is used for finding frequent itemset. The main concept of this algorithm is, it uses priori knowledge to generate frequent itemsets for association rules. Apriori uses a "Bottom Up" approach, where frequent subsets are extended one time at a time. Apriori uses breadth-first search and a hash tree structure to count candidate item-set efficiently. It uses iterative approach where k-itemsets are used to find $(\mathrm{K}+1)$ itemset. Apriori algorithm follows two step process consisting of join and prusne operations.

i. Join operation: To find $\mathrm{L}_{\mathrm{k}}$, a set of candidate $\mathrm{k}$-itemset is generated by joining $\mathrm{L}_{\mathrm{k}-1}$ with itself and ensure that no duplicate is generated.

ii. $\quad$ Prune step: $C_{k}$ is the superset of $L_{k}$. Remove the duplicate itemset in $C_{k}$, that is , itemset with less than support level. This itemset will be assign as $\mathrm{L}_{\mathrm{k}-1}$

Repeat the steps 1 \& 2 until there is no itemset with minimum support count.

The apriori algorithm pseudo code has given below;

Input: Transactional Database D, minsupport threshold.

Output: frequent itemset in D

Step 1: $L_{1}=$ frequent 1-itemset $(D)$

$$
\begin{gathered}
\text { Step 2: for }\left(k=2 ; L_{k-1}=\Phi ; k++\right) \\
\text { Step 3: Prune } 1\left(L_{k-1}\right) \\
\text { Step 4: } C_{k}=\text { apriori_gen }\left(L_{k-}\right. \\
\text { } ; \text { minsup })
\end{gathered}
$$

Step 5: \{

Step 6: $C=\operatorname{subset}\left(C_{k, t}\right)$

Step 7: for all candidates $c_{i} € C$

Step 8: $\{$ c.count ++$\}$ 


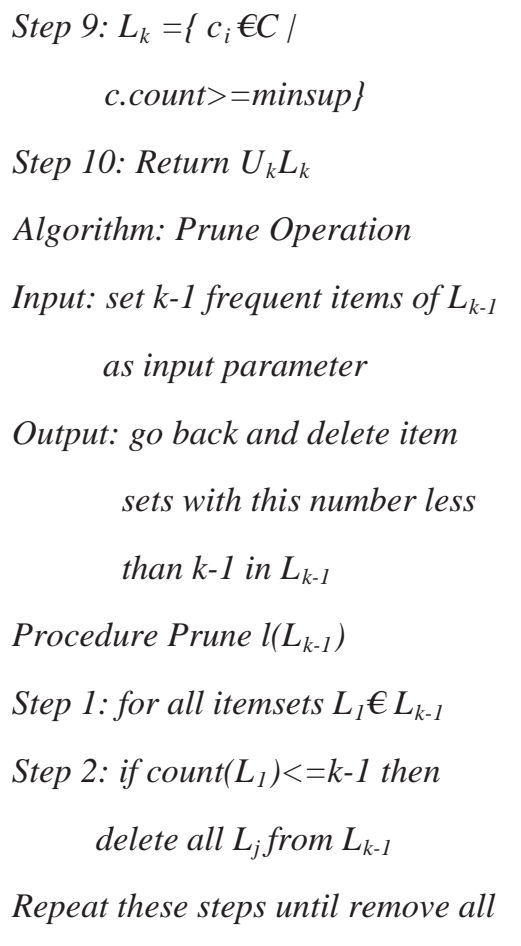

itemset with support count less than minsup.

The efficiency of apriori algorithm is improved by using the techniques namely, hash-based technique, transaction reduction, partitioning algorithm and sampling approach.

\section{The Apriori Algorithm : Example}

In a medical repositories most of the patient come for a particular disease, which is mentioned as primary disease. When Doctors or others associates make an interview with the patients and note down other diseases, which mentioned as secondary or associated diseases are inserted into a database [10]. The following table represents sample dataset of a medical database that contains the patient diseases.

Table 1 - Transactional Data Sample

\begin{tabular}{|l|l|}
\hline Patient ID & Diseases \\
\hline P001 & Cancer \\
\hline P002 & Heart Block \\
\hline P003 & Smoke \\
\hline P004 & Hypertension \\
\hline P005 & Cardiac Arrest \\
\hline
\end{tabular}

Consider a data sample which consists of 5 diseases. The following table represents a list of items(disease) consisting of 7 transactions. Here we take the minimum support is 2 .

1. We have to find out the frequent itemset using Apriori algorithm.

2. Then Association rules will be generated using min.suppot \& min.confidence. 


\begin{tabular}{|l|l|}
\hline TID & List of Items \\
\hline T100 & $11,13,15$ \\
\hline T100 & 12,14 \\
\hline T100 & 12,13 \\
\hline T100 & $11,12,14$ \\
\hline T100 & 11,13 \\
\hline T100 & $12,14,15$ \\
\hline T100 & $12,13,14,15$ \\
\hline
\end{tabular}

Step 1 : Generating 1-itemset Frequent Pattern

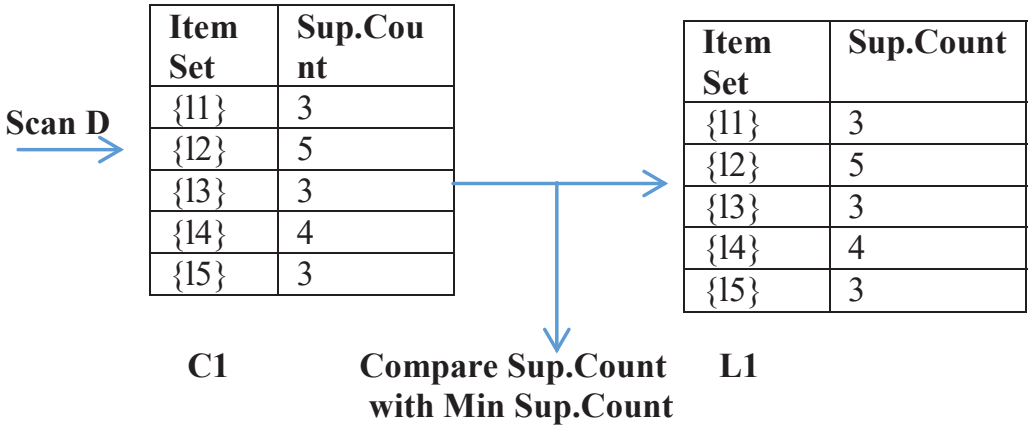

- $\quad$ The frequent 1-itemsets, L1, consists of the candidate 1-itemsets satisfying minimum support.

Step 2 : Generating 2-itemset Frequent Pattern

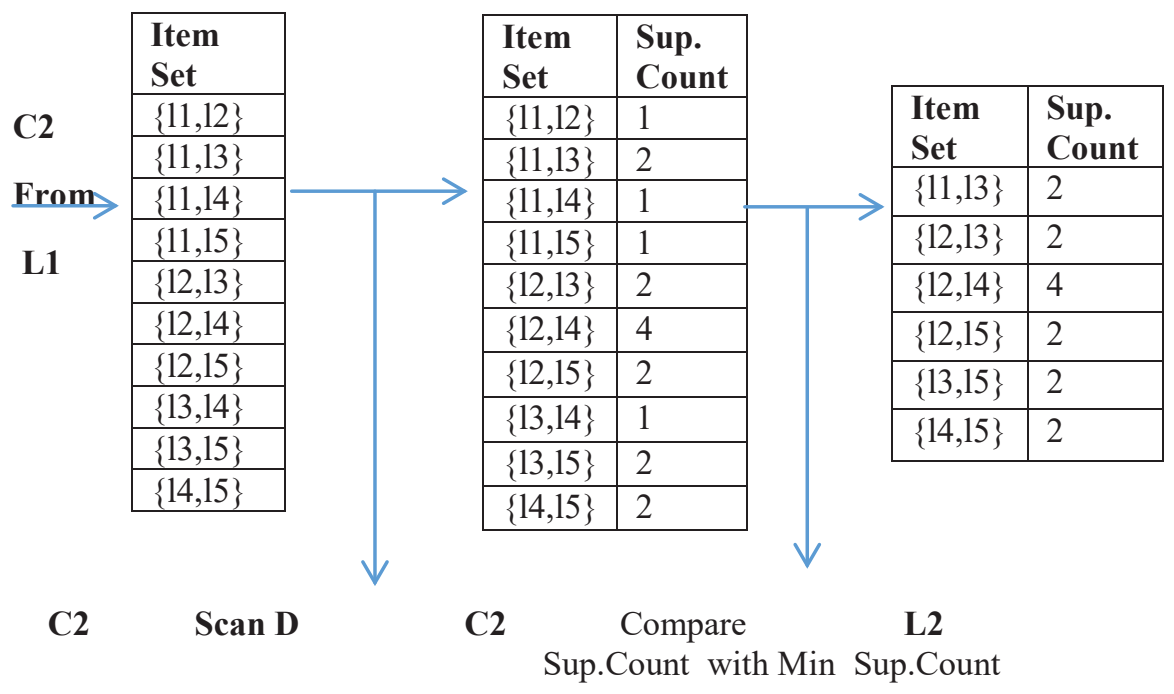

- The set of frequent 2-itemsets, L2, the algorithm uses L1 join L1 to generate a candidate set of 2-itemsets, $\mathrm{C} 2$.

- $\quad$ The set of frequent 2-itemsets, L2, consists of the candidate 2-itemsets in C2 having minimum support. Step 3 : Generating 3-itemset Frequent Pattern

- $\quad$ The generation of the set of candidate 3-itemsets, C3 use of the Apriori Property.

- $\quad$ To find C3, we compute L2 join L2. 
- $\quad \mathrm{C} 3=\mathrm{L} 2$ join $\mathrm{L} 2=\{\{12,13,14\},\{12,13,15\},\{12,14,15\}\}$.

$\longrightarrow$\begin{tabular}{|l|l|l|l|}
\hline Item Set \\
\hline$\{12,13,14\}$ \\
\hline$\{12,13,15\}$ \\
\hline$\{12,14,15\}$ \\
\hline
\end{tabular}$\rightarrow$\begin{tabular}{|l|l|l|} 
Item Set & $\begin{array}{l}\text { Sup. } \\
\text { Count }\end{array}$ \\
\hline$\{12,13,14\}$ & 1 \\
\hline$\{12,13,15\}$ & 1 \\
\hline$\{12,14,15\}$ & 2 \\
\hline
\end{tabular}$\rightarrow$\begin{tabular}{|l|l|} 
Item Set & $\begin{array}{l}\text { Sup. } \\
\text { Count }\end{array}$ \\
\hline$\{12,14,15\}$ & 2 \\
\hline
\end{tabular}

C3

C3

L3

- Lets take $\{12,14,15\}$. The 2 -item subsets of it are $\{12,14\},\{12,15\},\{14,15\}$. Since 2 -item subsets of $\{12,14,15\}$ are members of $\mathrm{L} 2$, will keep $\{12,14,15\}$ in $\mathrm{C} 3$.

- $\quad$ Therefore $\mathrm{C} 3=\{12,14,15\}$ after checking for all members of results of join operation for pruning.

- The transactions in D are scanned to determine L3, consisting of candidates 3-itemset in C3 having minimum support.

Step 4: Association Rules from Frequent Itemsets

- Lets minimum confidence threshold is, $70 \%$.

- The association rules are shown below,

$\mathrm{R} 1: 12^{\wedge} 14->15$

- $\quad$ Confidence $=\operatorname{sc}\{12,14,15\} / \operatorname{sc}\{12,14\}=2 / 4=50 \%$

- $\mathrm{R} 1$ is Rejected.

$\mathrm{R} 2: 12^{\wedge} 15 \rightarrow 14$

- $\quad$ Confidence $=\operatorname{sc}\{12,14,15\} / \operatorname{sc}\{12,15\}=2 / 2=100 \%$

- $\quad \mathrm{R} 2$ is Selected.

R3 : $14^{\wedge} 15->12$

- Confidence $=\operatorname{sc}\{12,14,15\} / \operatorname{sc}\{14,15\}=2 / 2=100 \%$

- $\mathrm{R} 3$ is Selected.

In this way, we have found three strong association rules.

2. Description of Steps and Methods

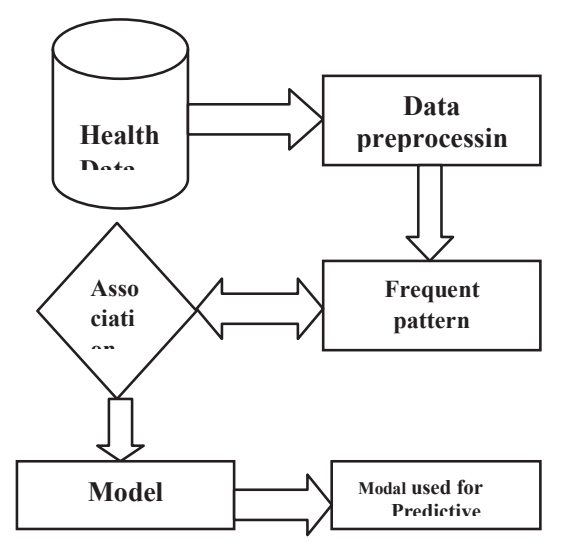

Fig 1. Model Generation process for predictive Co-occurrence of disease

We have selected the medical data from a diabetic specialty hospital for mining. Each record of the data describes the medical history of a patient. It contains information such as age, fasting sugar rate, post sugar rate, cholesterol rate, etc. the family history like whether the patient's parent has any disease like diabetic, cancer and heart problem. We collected all lab result for every patient. Totally we have collected 500 patients data. Our medical data has to convert to transaction format for applying association rule. We have considered all the data as discrete value filed. Let $\mathrm{A}_{1}, \mathrm{~A}_{2}, . . \mathrm{A}_{\mathrm{p}}$ be the attributes. We have applied the necessary preprocessing techniques to make the data a 
quality data. Table 2 describes the original data (sample only 5 records with few attributes) what we have collected from hospital. Table 3 shows the data after applying preprocessing technique. The numerical value of some of the fields are translated to discrete value.

Table 2 Sample data

\begin{tabular}{|l|l|l|l|l|l|l|l|l|}
\hline Age & $\begin{array}{l}\text { Blood } \\
\text { Glucose } \\
\text { level } \\
\text { Fasting } \\
\text { count }\end{array}$ & $\begin{array}{l}\text { Blood } \\
\text { Glucose } \\
\text { level } \\
\text { Post } \\
\text { prandial }\end{array}$ & Kidney(Urea) & Cholesterol & $\begin{array}{l}\text { Parent } \\
\text { diabetic }\end{array}$ & $\begin{array}{l}\text { Parent } \\
\text { Cancer }\end{array}$ & $\begin{array}{l}\text { Parent } \\
\text { heart } \\
\text { diseases }\end{array}$ & Smoke \\
\hline 43 & 178 & 234 & 56 & 189 & $\mathrm{Y}$ & $\mathrm{N}$ & $\mathrm{N}$ & $\mathrm{N}$ \\
\hline 56 & 110 & 135 & 89 & 234 & $\mathrm{~N}$ & $\mathrm{~N}$ & $\mathrm{~N}$ & $\mathrm{~N}$ \\
\hline 29 & 176 & 189 & 20 & 300 & $\mathrm{~N}$ & $\mathrm{~N}$ & $\mathrm{Y}$ & $\mathrm{N}$ \\
\hline 61 & 187 & 289 & 65 & 312 & $\mathrm{Y}$ & $\mathrm{Y}$ & $\mathrm{Y}$ & $\mathrm{Y}$ \\
\hline 66 & 67 & 110 & 34 & 267 & $\mathrm{~N}$ & $\mathrm{Y}$ & $\mathrm{Y}$ & $\mathrm{Y}$ \\
\hline
\end{tabular}

Table 3 Data after Preprocessing

\begin{tabular}{|l|l|l|l|l|l|l|l|l|}
\hline Age & $\begin{array}{l}\text { Blood } \\
\text { Glucose } \\
\text { level } \\
\text { Fasting } \\
\text { count }\end{array}$ & $\begin{array}{l}\text { Blood } \\
\text { Glucose } \\
\text { level } \\
\text { post- } \\
\text { prandial }\end{array}$ & $\begin{array}{l}\text { Kidney } \\
\text { (Urea) }\end{array}$ & Cholesterol & $\begin{array}{l}\text { Parent } \\
\text { diabetic }\end{array}$ & $\begin{array}{l}\text { Parent } \\
\text { Cancer }\end{array}$ & $\begin{array}{l}\text { Parent } \\
\text { heart } \\
\text { diseases }\end{array}$ & Smoke \\
\hline Adult & High & High & High & Low & Y & N & N & N \\
\hline Adult & Normal & Normal & High & Normal & N & N & N & N \\
\hline Young & High & High & Normal & High & N & N & Y & N \\
\hline Senior & High & High & High & High & Y & Y & Y & Y \\
\hline Senior & Low & Low & Normal & High & N & Y & Y & Y \\
\hline
\end{tabular}

Here in Table 2 we have identify attributes which are relevant to the mining process. Using this data we can generate an association rules that give who will have the chances of getting heart diseases. So we want to relate age, average sugar rate and cholesterol count. $40<$ age and Cholesterol $\leftarrow$ High and Parent diabetic $\leftarrow$ yes is an association rule with $60 \%$ support and $60 \%$ confidence, since it gives the detail about patient who will have the chances of getting heart diseases. If we relate the blood sugar level and cholesterol which leads to heart disease. If the doctor wants to relate the attributes blood Glucose level at fasting, post prandial and cholesterol then the rules generated by association helps to identify whether the patient have chances of getting heart disease or not. The rule $75<=$ age AND smoke $=>$ Yes is irrelevant because it does not make medical sense. So we have to relate causes to diseases.

\section{APPLYING RULES IN MEDICAL DATA}

Here we discussed the apriori algorithm to find association rules, then we explains the problems we found and improved version of the algorithm. In the first sets generate all rules that have support and confidence which is more than the minimum support and minimum confidence. The algorithm has two phases;

i. Generate frequent itemset by collecting all the itemsets that has more than the threshold support. First 1-itemset is generated and generate candidate by applying join operation on it and next 2- itemsets, then 3-itemsets are generated. This phase repeat until there is no frequent itemset.

ii. Generate rules for frequent itemset such as $\mathrm{x} \rightarrow \mathrm{y}$ with support 's' and minimum confidence 'c'.

There are some difficulties in association rules in the medical domain. They are association size, maximal frequent itemset, low support and high support. Some of the solution has proposed in [8]. This work is a preliminary one. Our algorithm implementation was done using Weka tool. The main aim of this work was to find the co-occurrence of diseases. In this work we have considered diabetic data sets. So we tried to find out what are 
co-occurrence diseases come with diabetic. The data set $\mathrm{n}$ consist of 500 patients having 50 attributes. First 11 most important attributes were selected for mining. We ran the association rule program with the selected attributes and discovered 47 association rule. All rules are not relevant without required result. The first important rule is Blood Glucose level at fasting AND cholesterol $\rightarrow$ heart disease with $60 \%$ support and $70 \%$ confidence. This rule is very much relate with this work. Similarly 6 rules are much closed to this expected outcomes. This rules were much useful for physicians who treat the diabetic patients. Thus data mining helped in getting knowledge from massive data.

\section{CONCLUSION}

In this work we have implemented association rule mining on apriori algorithm which will be more useful for medical data. We briefly explains the association rule and apriori algorithm. We have implemented the association rule on selected medical data with the help of simulation tool and we generated set of association rules. We examined all the generated association rule and selected only 7 relevant rules as most important rule to our work. We recommend association rule can be used for many medical domain to take a proper decision to treat and prevent the patient from panic diseases. Based on this work a predictive model is proposed to diagnose early diseases. For automation and accurate result, this work needs to include other kind of diseases like kidney based problems, brain related other diseases.

\section{REFERENCES}

[1] Agrawal, R., Imielinski, T \& Swami A. Mining association rules between sets of items in large databases, Proceedings of ACM SIFMOD international conference on management of data, New York, pp. 207-216, 1993.

[2] Hanauer, D. A., Rhodes, D.R. \& Chinnaiyan, A.M. Exploring Clinical associations using -omics based enrichment analyses PLoS One, 4(4) E5203 2009.

[3] Ordonez, C., Ezquerra, N.F \& Santana, C. A. Constraining and summarizing association rules in medical data., Knowledge and information Systems, 3, pp. 1-2, 2006.

[4] Paetz J \& Brause R W, A frequent patterens tree approach for rule generation with categorical septic shock patient data. Proceddings of the second international symposium on medical data analysis, London: Springer - Verlag, pp 207-12, 2001.

[5] D. Kerana Hanirex, and M.A. Dorai Rangaswamy. 2011. Effi-cient Algorithm for Mining Frequent Itemsets using Clustering Techniques. International Journal on Computer Science and Engi-neering (IJCSE) Vol. 3 No. 3 March 2011.

[6] E. Ramaraj and N. Vankatesan, - Bit Stream Mask Search Algo-rithm in Frequent Itemset Mining,„ European Journal of Scien-tific Reasearch,\| Vol. 27 No. 2 (2009), pp. 286-297

[7] J.5 Han, J. Pei and Y.Yin, -Mining Frequent Patterns without Candidate Generation: A Frequent-Pattern Tree Approach, In Proceedings ACM-SIGMOD International Conference Man-agement of Data (SIG MOD’04), pages 53-87, 2004

[8] M. H. Marghny and A.A. Mitwaly, —Fast Algorithm for Mining Association Rules, „I In proceedings of the First ICGST Interna-tional Conference on Artificial Intelligence and Machine ELearning AIML05, pages 36-40, Dec. 2005

[9] S. Prakash and R.M.S. Parvathi, - An Enhanced Scaling Apriori for Association Rule Mining Efficiency,\| European Journal of Scientific Research, Vol. 39 No. 2 (2010), pages 257-264

[10] A. Mahmood Rashid, Md Tamjidul Hoque and Abdul Sattar, - Association Rules Mining Based Clinical Observations. Institute for Integrated and Intelligent Systems (IIIS). 